УДК 159.9

\title{
НАВЫКИ ПИТАНИЯ И УРОВЕНЬ ТРЕВОЖНОСТИ У ЛЮДЕЙ С ЗАБОЛЕВАНИЯМИ ЖЕЛУДОЧНО-КИШЕЧНОГО ТРАКТА
}

\author{
Илич Мария \\ Научный руководитель: Чапала Татьяна Владимировна \\ к.псх.н., доцент \\ ФГБОУ ВО «Тольяттинский государственный университет»
}

\begin{abstract}
Аннотация: В статье представлены результаты исследования, которое проводилось в городе Тольятти на базе гастроэнтерологического отделения Тольяттинской городской клинической больницы № 5. В исследовании приняло участие 95 человек, распределённых в двух группах, первая группа 55 человек с заболеваниями желудочно-кишечного тракта и вторая группа 40 здоровых человек. Полученные результаты эмпирического исследования показали, что люди с гастроэнтерологическими заболеваниями питаются не регулярно, не сбалансировано и не дробно. У них наблюдаются признаки зависимости от сладкой, солёной и жирной пищи. В сравнении с контрольной группой у них определяются значимые статистические различия в уроне ситуативной и личностной тревожности.
\end{abstract}

Ключевые слова: Навыки питания, ситуативная тревожность, личностная тревожность, заболевания желудочно-кишечного тракта, признаки пищевой зависимости.

\section{EATING HABITS AND THE LEVEL OF ANXIETY IN PEOPLE WITH DISEASES OF THE GASTROINTESTINAL TRACT}

\section{Ilich Mariya Chapala Tatyana Vladimirovna}

\begin{abstract}
The article presents the results of a study conducted in the city of Togliatti on the basis of the Gastroenterology Department of the Togliatti city clinical hospital no. 5. The study involved 95 people who were divided into two groups, a feather group of 55 people with diseases of the gastrointestinal tract and 40 healthy people. The results of an empirical study showed that people with
\end{abstract}


gastroenterological diseases do not eat regularly, balanced and fractional, there are signs of dependence on sweet, salty and fatty foods. They also have significant statistical differences in the damage value of state and trait anxiety, when compared with the control group.

Key words: Eating habits, state anxiety, trait anxiety, diseases of the gastrointestinal tract, signs of food addiction.

Объективные статистические данные, собранные в России, демонстрируют тенденцию роста заболеваний желудочно-кишечного тракта среди людей среднего возраста, трудоспособного населения [1], раннего юношеского возраста, студентов [2] и детей школьного возраста [3]. Неправильные (нездоровые) привычки питания часто могут быть причиной развития соматических заболеваниях, в том числе и заболеваний гастроэнтерологического профиля. Изучение особенностей питания людей с заболеваниями желудочно-кишечного тракта, выявляет, у большинства пациентов высокий процент неправильно сформированных навыков питания с тенденцией проявления негативных эмоциональных состояний, чаще тревожности (высокий уровень личностной и реактивной тревожности) [4].

Современные зарубежные исследования японских учёных (Yasuhiro Sato, Shin Fukudo, 2015), подтверждают связи негативных эмоциональных проявлений (состояние стресса, тревожность, депрессивность) и неправильных навыков питания у больных людей с заболеваниями гастроэнтерологического профиля [5].

Негативные эмоциональные состояния, такие как страх, стрессы, тревога, депрессивные состояния сопутствуют развитию непреодолимого желания принять пищу. Принимая пищу импульсивно, человек получает удовольствие и не осознает как отрицательные эмоции временно отступают (на определённое время). Чувство сытости для взрослого человека, как и для младенца, эквивалентно защищённости и безопасности. Нарушение данного баланса может, повлиять на психологическое и соматическое здоровье, и привести к развитию заболеваний.

Цель исследования: Изучение навыков питания и уровня ситуативной и личностной тревожности у пациентов с заболеваниями желудочно-кишечного тракта.

Представленное исследование проводилось на базе стационарного отделения гастроэнтерологии Тольяттинской городской клинической 
больницы № 5 г. Тольятти, с оформленным положительным решением комиссии Комитета по биоэтике при Самарском медицинском государственном университете.

В исследовании приняло участие 95 человек, из них 71 женщина и 24 мужчин в возрасте от 18 до 83 лет. Первую группу - экспериментальную составили 55 человека с заболеваниями гастроэнтерологического профиля разных клинических форм. Вторую группу - контрольную выбрано 40 здоровых человек, из них 18 из числа родственников посещающих больных и 22 здоровые граждане пожелавшие принять участие в исследовании.

В исследовании применялись следующие методы: психологическая беседа, авторская анкета исследующая социально-психологические характеристики, методика исследования ситуативной и личностной тревожности Спилбергера-Ханина.

Результаты анкеты и психологической беседы проведённого эмпирического исследования позволяют определить следующе (рис. 1):

71\% больных людей с заболеваниями желудочно-кишечного тракта, питаются не разнообразно, основной рацион питания состоит чаще из углеводов и жиров. Ежедневно меню питания состоится из жирных сортов мяса (свинина) и сыра, макаронных изделий, картофеля, крупы, хлеба, сладостей (конфеты и кондитерские изделия). В питании практически отсутствуют свежие овощи и фрукты, рыба и кисломолочные продукты. И только 29\% испытуемых первой группы, стараются питаться, разнообразно и сбалансировано.

У большинства людей с гастроэнтерологическими заболеваниями (68\%) были выявлены пищевые пристрастия к определённой пище (сладкую, жирную и солёную), у $32 \%$ не наблюдается.

Подавляюще большинство участников первой группы (87\%) не соблюдает рекомендованную диету врачом, которая предполагает дробное питание (пятиразовое). И только $13 \%$ испытуемых с заболеваниями желудочно-кишечного тракта старается, соблюдают рекомендации по питанию. 


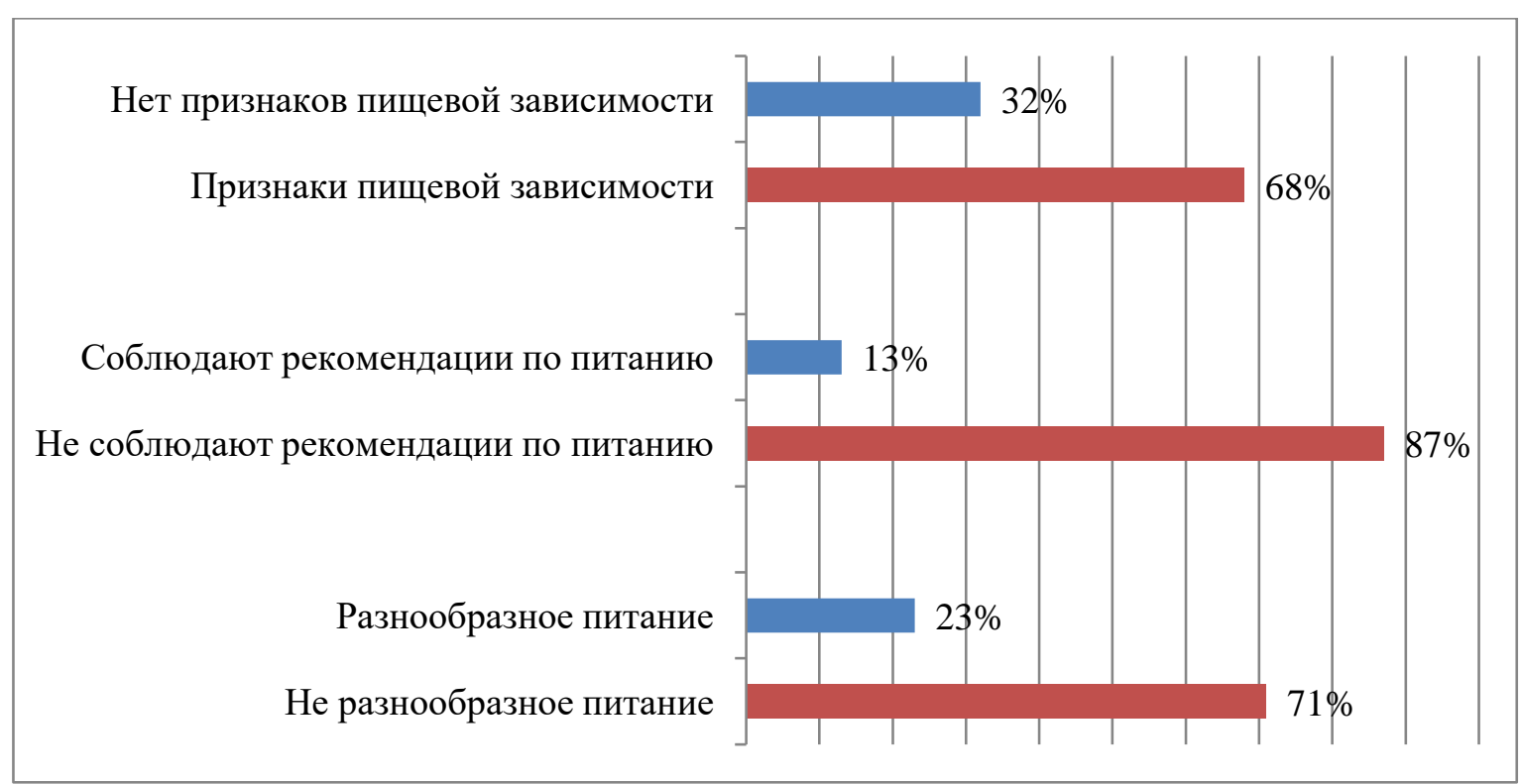

Рис. 1. Анализ навыков питания людей с заболеваниями желудочнокишечного тракта (55 человек)

Проведённая психологическая диагностика эмоционального состояния (уровня ситуативной и личностной тревожности) людей с заболеваниями желудочно-кишечного тракта и контрольной группы выявила:

Высокий уровень значений ситуативной тревожности был выявлен у $78 \%$ первой группы и у 57\% контрольной группы; средней уровень баллов был определён у $20 \%$ пациентов с заболеваниями желудочно-кишечного тракта и $42 \%$ у здоровых людей; низкое значение баллов было определённо только у $2 \%$ испытуемых первой группы, у участников контрольной группы не определяется низкое значение баллов реактивной тревожности.

Сравнительный анализ, результатов психологической диагностики уровня ситуативной тревожности пациентов гастроэнтерологического профиля и контрольной группы, определил статистические значимые различия уровня тревожности как состояния $(\mathrm{F}=14,624$, при $\mathrm{p}=0,000<0,001)$ (рис. 2). 


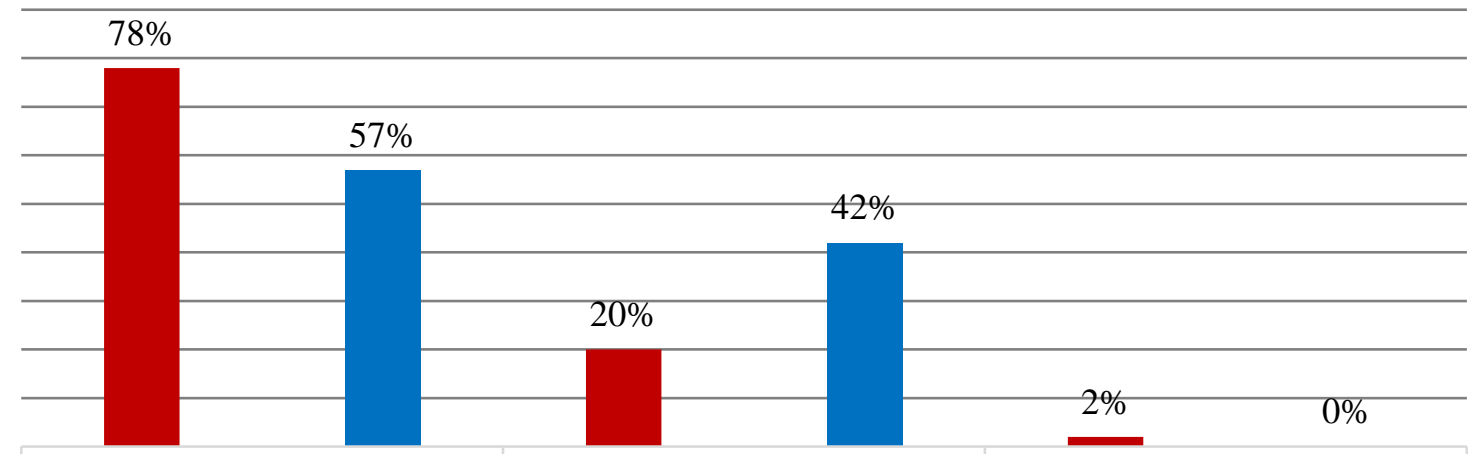

Первая группа Вторая группа Первая группа Вторая группа Первая группа Вторая группа СТ- высокая

СТ- средняя

СТ-низкая

Рис. 2. Соотношение результатов диагностики ситуативной тревожности в испытуемых группах (СТ - ситуативная тревожность)

Высокий уровень значений личностной тревожности определяется у $87 \%$ участников исследования первой группы и 55\% второй группы; средней уровень был определён у $13 \%$ людей с заболеваниями желудочно-кишечного тракта и $45 \%$ у здоровых людей. Низких уровень значения баллов тревожности как свойства личности не определяется у участников первой группы, так и у контрольной группы. Выявление значимые статистические различия в уровне личностной тревожности у пациентов гастроэнтерологического профиля и здоровых людей контрольной группы исследования $(\mathrm{F}=22,915$,при $\mathrm{p}=0,000<0,001)$ (рис. 3).

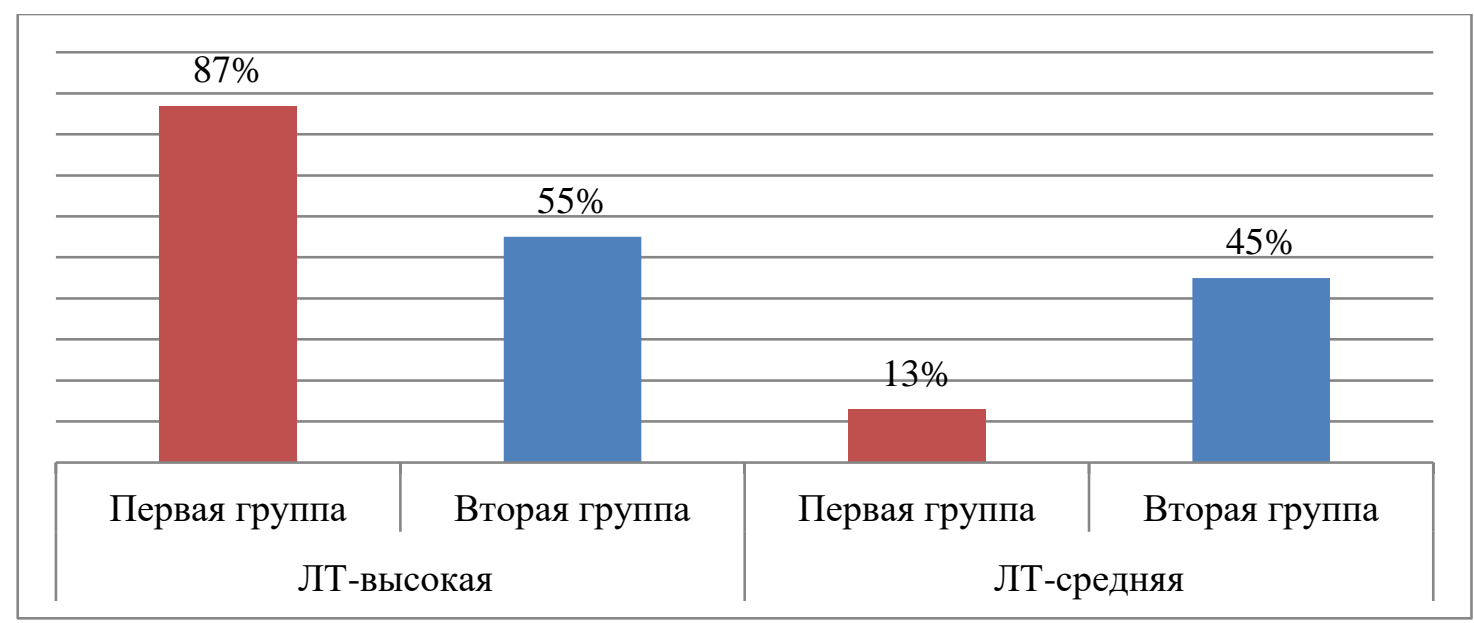

Рис. 3. Соотношение результатов диагностики личностной тревожности в испытуемых группах (ЛТ - личностная тревожность) 
Авторы исследования предполагали, что существуют значимые различия в уровне значения тревожности у родственников больных людей и людей пожелавших принять участие в исследовании, было проведено соотношение значения баллов по ситуативной и личностной тревожности. Однако, различия в уровне значений баллов ситуативной $(\mathrm{F}=0,264$, при $\mathrm{p}=$ $0,609>0,05)$ и личностной $(\mathrm{F}=3,105$, при $\mathrm{p}=0,086>0,05)$ тревожности, между участниками контрольной группы исследования, не были выявлены (рис. 4).

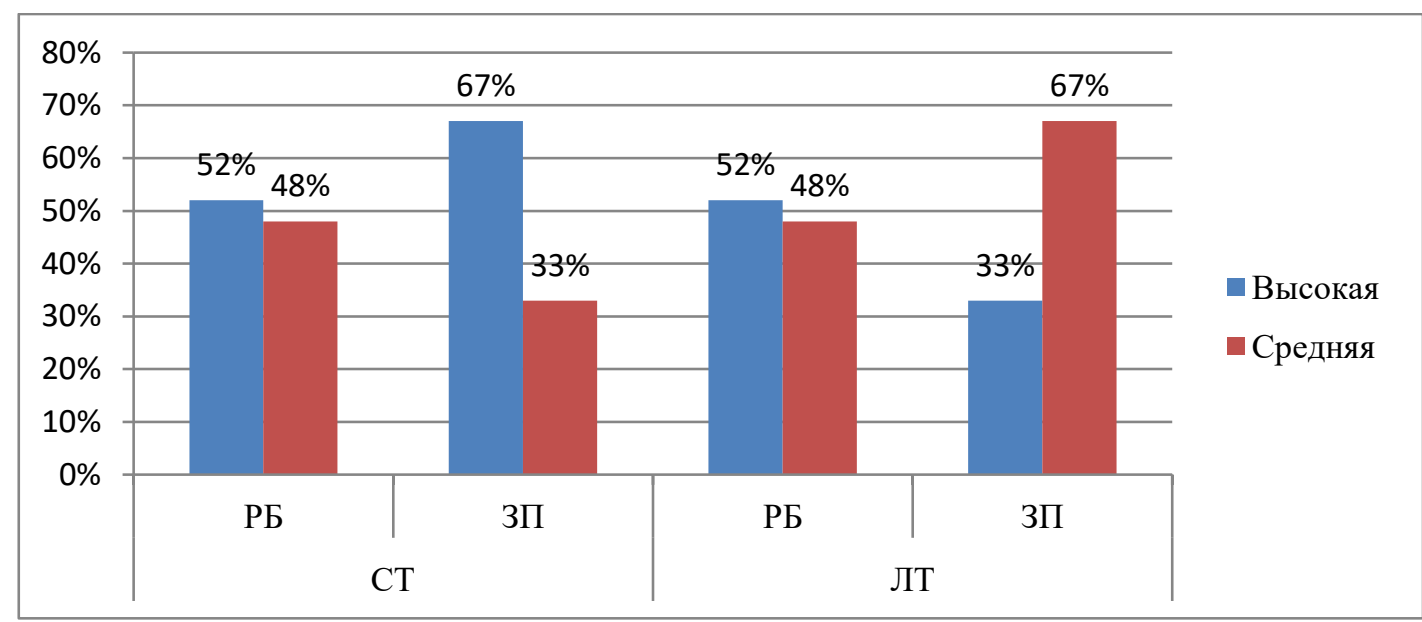

Рис. 4. Соотношение результатов диагностики ситуативной и личностной тревожности у испытуемых контрольной группы (РБ-родственники больных людей; ЗП-здоровые люди пожелавшие принять участие в исследовании)

Результаты проведённого исследования позволяют сделать вывод:

- люди с заболеваниями желудочно-кишечного тракта не соблюдают рекомендации питания которые предполагает дробность, разнообразие и сбалансированность питания. У них наблюдаются признаки зависимости к сладкой, солёной и жирной пищи (данная пища не рекомендуется в ежедневном рационе пациентов с гастроэнтерологическими заболеваниями).

Исследованием тревожности у людей с заболеваниями желудочнокишечного тракта определяются значимые статистические различия, в уровне значений реактивной и личностной тревожности. При сравнении с контрольной группой, уровень значения выше у пациентов гастроэнтерологического профиля.

Полученные результаты в исследовании можно учитывать при разработке профилактических и просветительских психологических программ 
для широкой группы населения, в практике медицинских психологов работающих с людьми с заболеваниями желудочно-кишечного тракта.

\section{Список литературы}

1. Российский статистический ежегодник. 2018: статистический сборник. М.: Росстат. - 2018. - 694 с.

2. Лебедева У.М., Баттахов П.П., Степанов К.М., Лебедева А.М., Занковский С.С., Булгакова Л.И., Винокурова Д.М. Организация питания детей и подростков на региональном уровне // Вопросы питания. - 2018. - № 6(87). - С. 48-56.

3. Александров А.А., Порядина Г.И., Котова М.Б., Иванова Е.И. Особенности пищевого поведения детей и подростков крупных городов (на примере школьников Москвы и Мурманска) // Вопросы питания. - 2014. - № 4(83). - C. 67-74.

4. Чапала Т.В., Илич М. Исследование социально-психологических характеристик и тревожности у пациентов гастроэнтерологического профиля (на примере хронического панкреатита) // Вектор науки Тольяттинского государственного университета. Серия: Педагогика, психология. - 2019. - Т. 39. - № 4. - C. 58-64.

5. Yasuhiro S., Shin F. Gastrointestinal symptoms and disorders in patients with eating disorders // Clinical Journal of Gastroenterology. - 2015. - № 8(5). -P. 255-63.

(C) М. Илич, Т.В. Чапала, 2020 